\title{
Self-assembly of Sn-3Ag-0.5Cu Solder in Thermoplastic Resin Containing Carboxyl Group and its Interconnection
}

\author{
KAZUHIRO MIYAUCHI, ${ }^{1,3}$ YUKIHIKO YAMASHITA, ${ }^{1}$ NAOYA SUZUKI, ${ }^{1}$ \\ and NOZOMU TAKANO ${ }^{2}$ \\ 1.-Tsukuba Research Laboratory, Hitachi Chemical Co., Ltd., 48 Wadai, Tsukuba, Ibaraki 300- \\ 4247, Japan. 2.-Advanced Performance Materials Operational Headquarters, Hitachi Chemical \\ Co., Ltd., 14 Goi-minamikaigan, Ichihara, Chiba 290-8567, Japan. 3.—e-mail: kaz-miyauchi@ \\ hitachi-chem.co.jp
}

\begin{abstract}
The self-assembly of solder powder on pads is attractive as a novel interconnection method between chips and substrates. However, the solder used in this method is limited to $\mathrm{Sn}-58 \mathrm{Bi}$ and $\mathrm{Sn}-52 \mathrm{In}$. In contrast, $\mathrm{Sn}-3 \mathrm{Ag}-0.5 \mathrm{Cu}$ has been relatively less studied despite its wide use as a lead-free solder in assembling semiconductor packages. Hence, here, polymeric materials incorporating $\mathrm{Sn}-3 \mathrm{Ag}-0.5 \mathrm{Cu}$ solder powder were investigated for the self-assembly of the solder on pads at temperatures up to $260^{\circ} \mathrm{C}$ in a lead-free reflow process. The self-assembly of the solder was observed with an optical microscope through transparent glass chips placed on substrates covered with the polymeric materials incorporating the solder powder. Differential scanning calorimetry measurements were performed to confirm the behaviors of the reaction of the resins and the melting of the solder. When epoxy resin with a fluxing additive was used as a matrix, self-assembly of the solder was prevented by the cross-linking reaction. Conversely, when thermoplastic resin containing carboxyl groups was used as a matrix, the self-assembly of solder was successfully achieved in the absence of fluxing additives. The shear strength of interconnection using reflowfilm with lamination was sufficient and significantly increased during the reflow process. However, the shear strength of the reflowfilm showed cohesive failure, possibly because of the brittle intermetallic compounds ( $\left.\mathrm{Ag}_{3} \mathrm{Sn}, \mathrm{Au}_{4} \mathrm{Sn}\right)$ network in bulk was lower than that of conventional solder paste that showed interfacial failure after the reflow process with a rapid cooling rate.
\end{abstract}

Key words: Self-assembly, Sn-3Ag-0.5Cu solder, interconnection, thermoplastic resin containing carboxyl groups, shear strength, intermetallic compound (IMC)

\section{INTRODUCTION}

The flip-chip (FC) technology, termed as C4 (controlled collapse chip connection), for soldering interconnections of fine pitch pads is widely used for assembling semiconductor packages. ${ }^{1}$ The advantageous property of the FC interconnection technology is the lower electrical resistance of the conductive path between the chip and substrate, owing to the intermetallic compound (IMC) between

(Received October 30, 2013; accepted June 12, 2014;

published online July 11, 2014) the solder and pad when compared with that of the mechanical contact of anisotropic conductive adhesives (ACAs). ${ }^{2,3}$ Further improvement of the FC technology is desired for expanding future applications. ${ }^{1,4,5}$

One of the novel improvements involves the selfassembly of solder using thermoset resin, namely, epoxy resin and solder powder, Sn-58Bi. ${ }^{6-11}$ Figure 1 shows the method employed for the selfassembly of the electrically conductive path of solder between the pads and the concurrent formation of underfill during the reflow process. This method is also academically attractive because it involves self-assembly, which is one of the hot scientific 


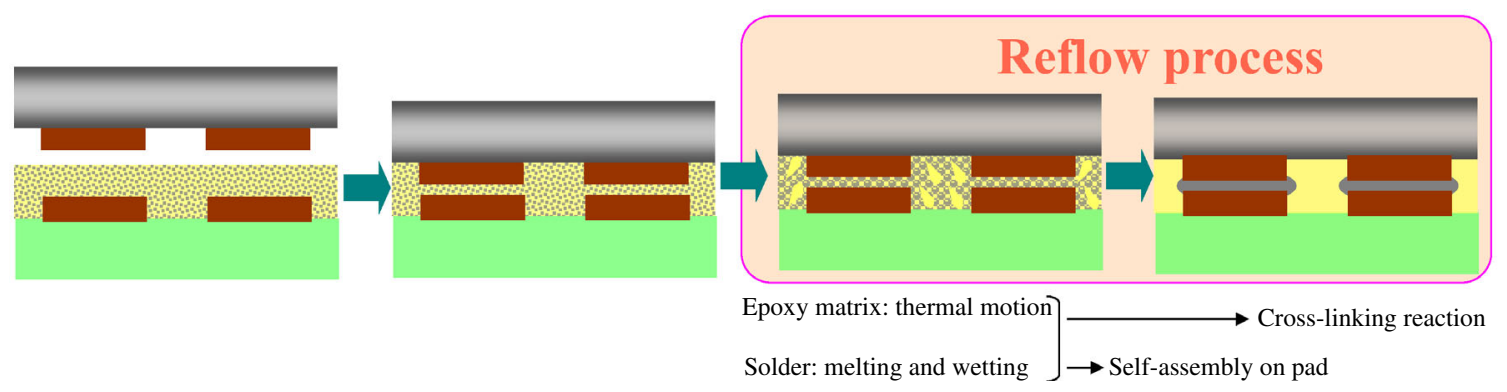

Fig. 1. Self-assembly process of solder for interconnection between chip and substrate during reflow process.

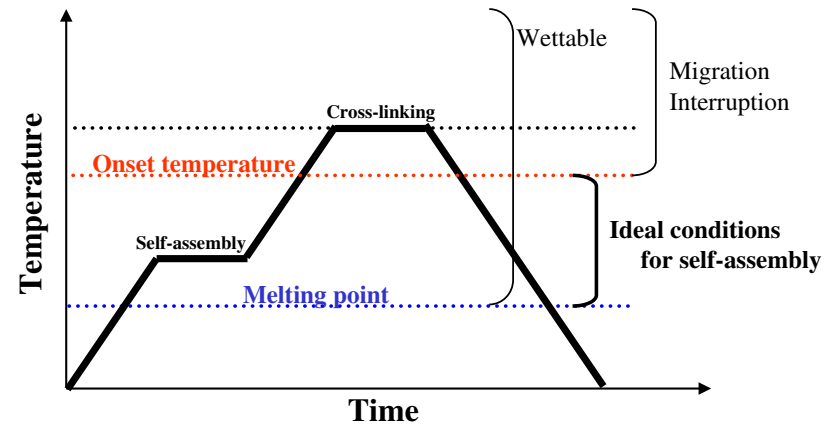

Fig. 2. Reflow process for the self-assembly of solder, such as $\mathrm{Sn}-58 \mathrm{Bi}$, which features a melting point temperature lower than the onset temperature of cross-linking of epoxy resin.

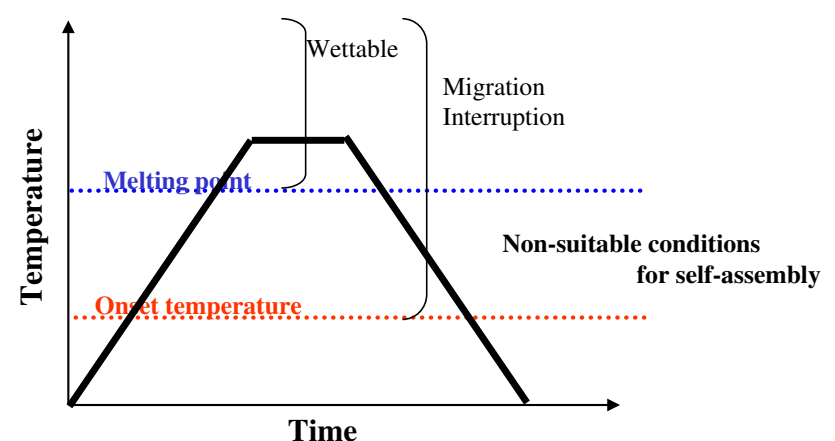

Fig. 3. Reflow process of solder, such as $\mathrm{Sn}-3 \mathrm{Ag}-0.5 \mathrm{Cu}$, which features a melting point temperature higher than the onset temperature of cross-linking of epoxy resin. Self-assembly does not proceed under these conditions.

topics, ${ }^{12-14}$ and is industrially remarkable as reported by many authors. ${ }^{2,3,15-20}$ In these studies, low-temperature solders were used to self-assemble at temperatures lower than the onset temperature $\left(\sim 150^{\circ} \mathrm{C}\right)$ of the cross-linking reaction of the epoxy. The typical low-temperature solders studied were $\mathrm{Sn}-58 \mathrm{Bi}\left(T_{\mathrm{m}} 139^{\circ} \mathrm{C}\right)$ and $\mathrm{Sn}-52 \mathrm{In} \quad\left(T_{\mathrm{m}} 118^{\circ} \mathrm{C}\right)$. Figure 2 shows the reflow process used for the selfassembly of low-temperature solder and underfilling with epoxy. ${ }^{8}$

Despite the advantages and extensive research performed on these solders to date, $\mathrm{Sn}-58 \mathrm{Bi}$ solder

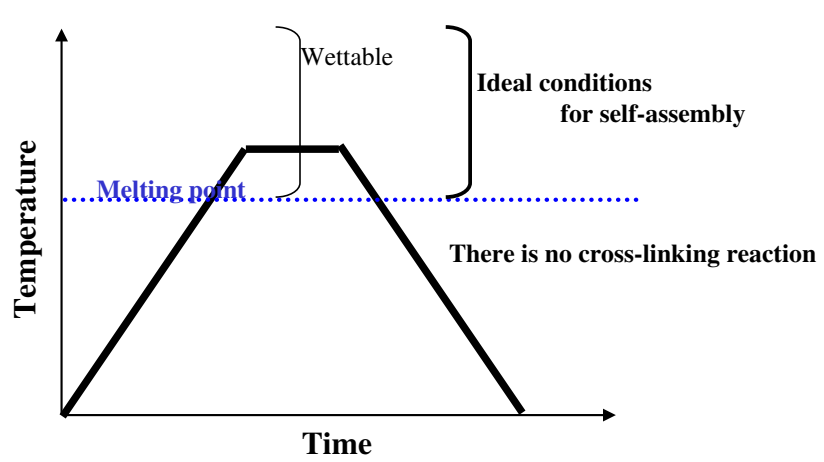

Fig. 4. Reflow process for the self-assembly of solder in thermoplastic resin.

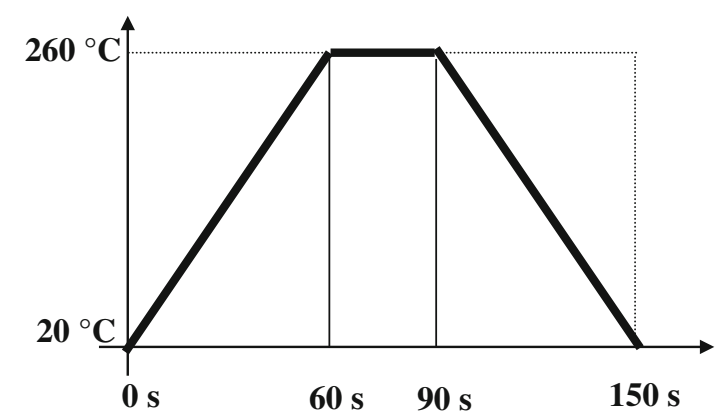

Fig. 5. Reflow process adopted in this study in the presence of leadfree solder $\mathrm{Sn}-3 \mathrm{Ag}-0.5 \mathrm{Cu}$.

has an inherent drawback, i.e., its reliability declines as a function of thermal history. ${ }^{21-27}$ Additionally, Sn-52In solder is expensive. Accordingly, $\mathrm{Sn}-3 \mathrm{Ag}-0.5 \mathrm{Cu}$ solder has been recommended by the Japan Electronics and Information Technology Industries Association (JEITA), and is widely used in FC interconnections. ${ }^{28-31}$ However, as shown in Fig. 3, cross-linking of epoxy prevents Sn-3Ag-0.5Cu solder from self-assembling because the cross-linking reaction starts at a temperature below the melting and assembling temperatures of the solder.

Accordingly, in this study, thermoplastic resin that does not cross-link even at high temperatures 


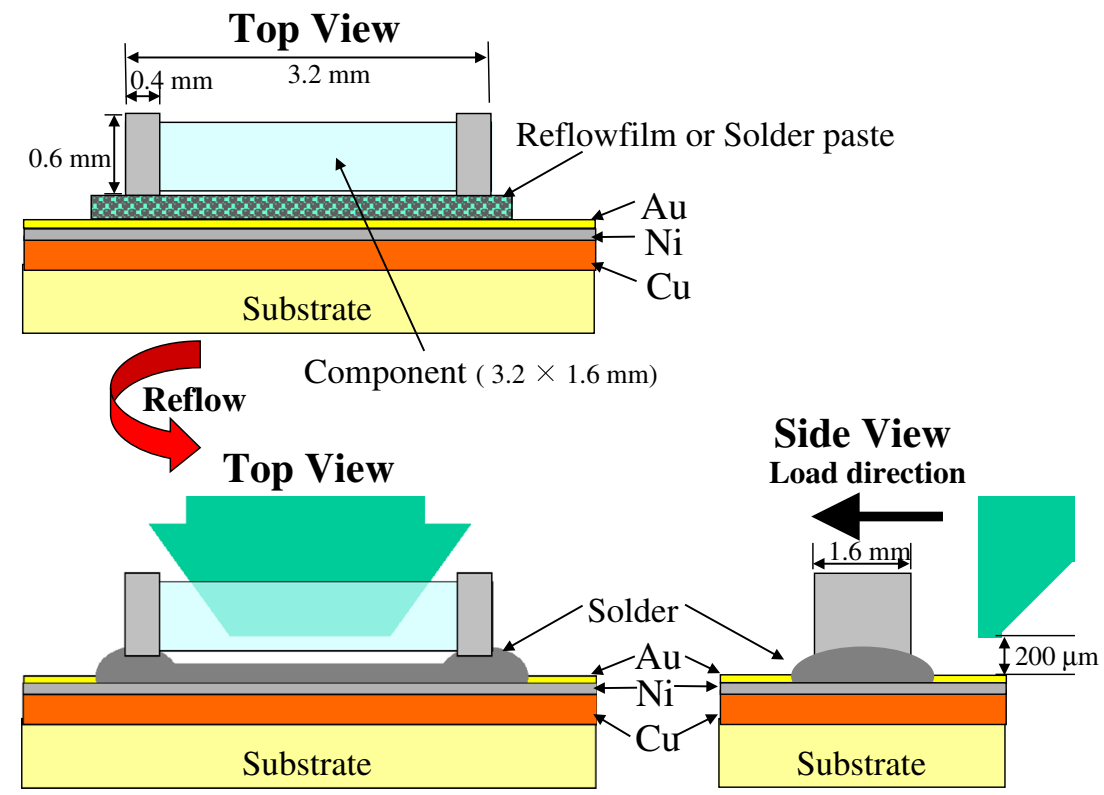

Fig. 6. Schematic diagram of the shear test conducted on the 3216 component mounted on the ENIG surface finish of the FR-4 substrate.

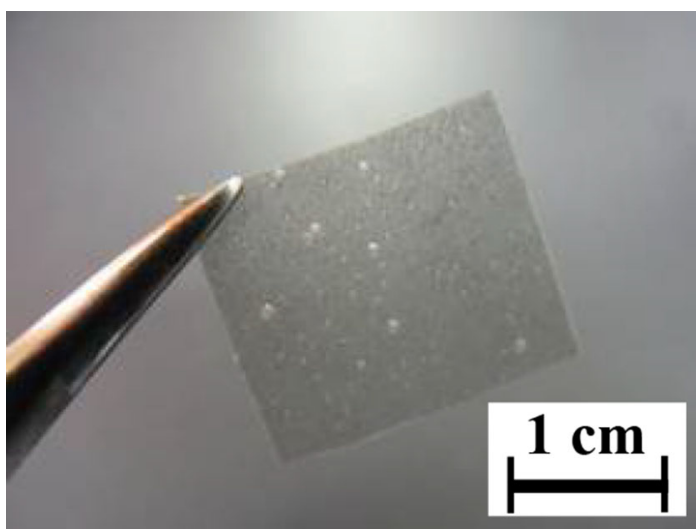

Fig. 7. Photographic image of reflowfilm.

of $\sim 260^{\circ} \mathrm{C}$ in the current lead-free reflow process was studied as a matrix to achieve self-assembly of $\mathrm{Sn}-3 \mathrm{Ag}-0.5 \mathrm{Cu}$ solder. The process using this material system is shown in Fig. 4. The thermoplastic resin used in this study shows excellent flux activity, owing to the carboxyl groups, and also has excellent film formability that facilitates handling and repair, owing to the relatively high molecular weight. This is the first report on the development of thermoplastic resin film containing solder powder that is termed reflowfilm.

\section{EXPERIMENTAL}

\section{Materials and Test Specimens Preparation for the Self-assembly of the Solder}

Thermoplastic resin containing carboxyl groups, $\mathrm{Sn}-3 \mathrm{Ag}-0.5 \mathrm{Cu}$ solder powder (average diameter:

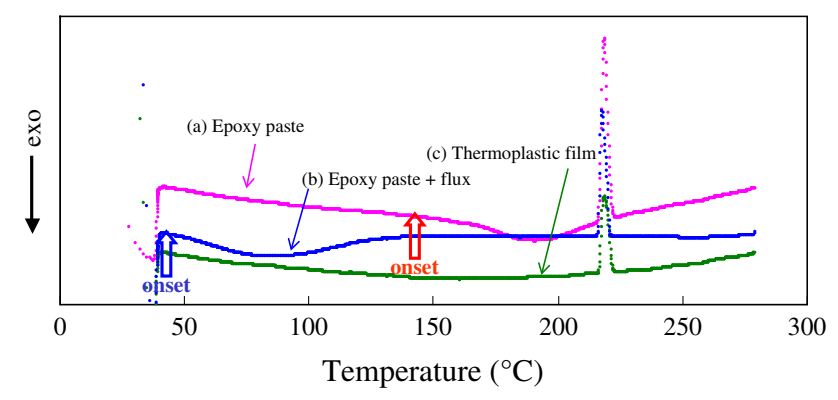

Fig. 8. DSC curves of (a) epoxy paste, (b) epoxy paste containing fluxing agent, and (c) thermoplastic film. The samples were heated at a rate of $10^{\circ} \mathrm{C} / \mathrm{min}$.

$\sim 30 \mu \mathrm{m}$ ), and organic solvent were mixed to produce a varnish solution. The latter solution was cast on a poly(ethylene terephthalate) (PET) film and ovendried to form a film incorporating the solder powder (reflowfilm) of $\sim 150 \mu \mathrm{m}$ thickness. Also, an epoxy paste was formed by mixing liquid epoxy resin, curing agent, and solder powder. In addition, epoxy paste incorporating a fluxing agent was prepared. The obtained film or pastes were placed on a substrate onto which a transparent glass chip was placed, forming a sandwich structure (glass/film/ substrate) to monitor the flow of the solder. The substrate used was FR-4 (flame retardant type 4) of a glass fiber-reinforced epoxy resin containing pads of $1.3 \mathrm{~mm}$ in diameter with $2.0-$ and $2.2-\mathrm{mm}$ pitches; areas of the substrate surface that did not contain the pads were covered with solder resist. The $\mathrm{Cu}$ pad on the substrate was coated with $\mathrm{Ni} / \mathrm{Au}$, termed as ENIG (electroless nickel immersion gold). To 
Direction of observation

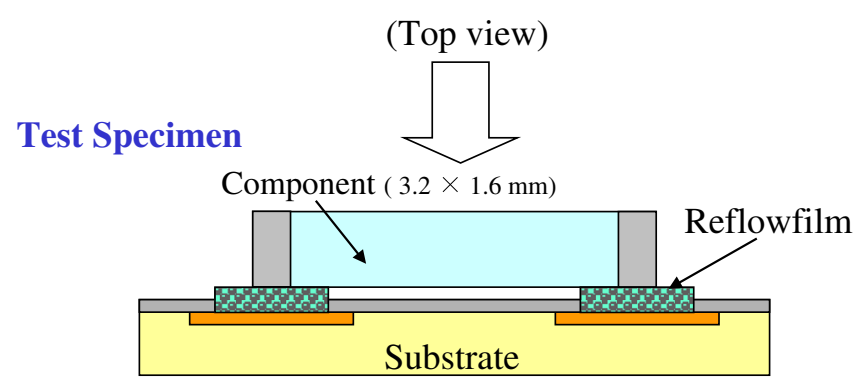

(a) Before reflow

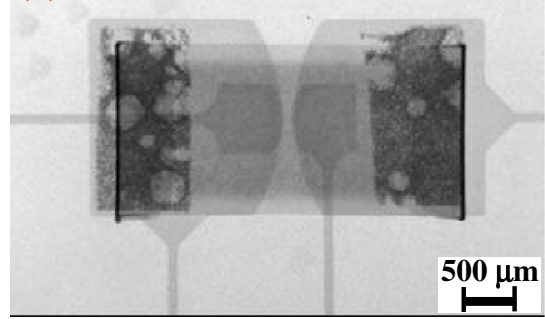

(b) After Reflow

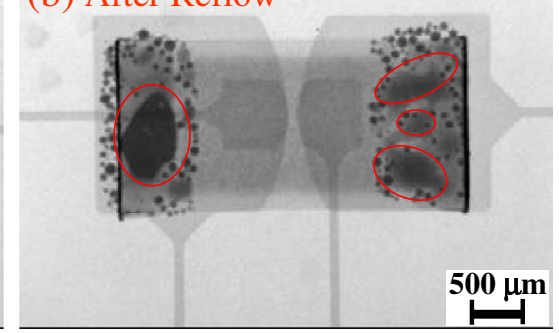

Fig. 9. X-ray transmission images of the interconnection between the 3216 component and substrate (a) before and (b) after the reflow process.

\section{Test Specimen}

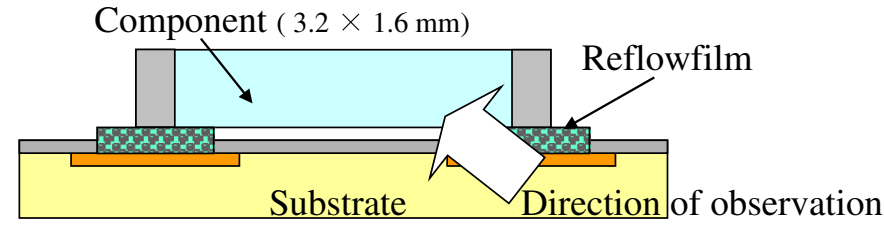

(side view)

(a) Before reflow

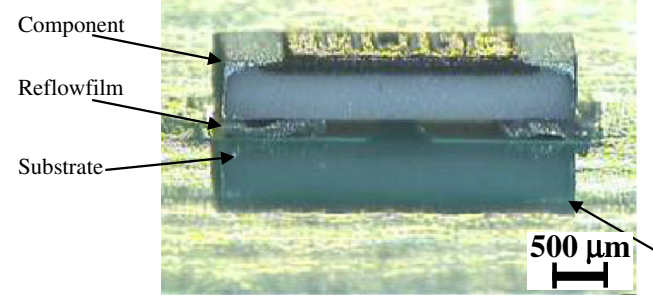

(b) After Reflow

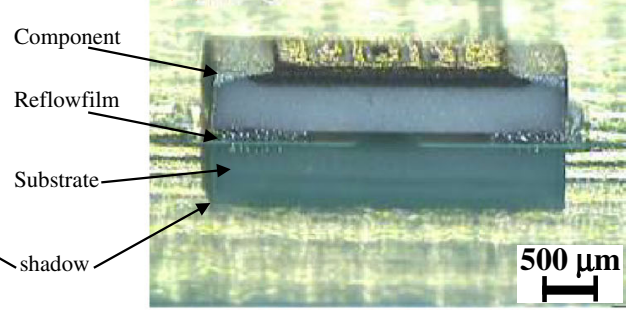

Fig. 10. Optical images of the interconnection between the 3216 component and substrate (a) before and (b) after the reflow process.

observe the interconnection between pads, a 3216 component [Koa, Japan; Japanese Industrial Standard (JIS) 3216: $3.2 \mathrm{~mm} \times 1.6 \mathrm{~mm}$, Electronic Industries Alliance (EIA) standard 1206: 1.2 in. $\times$ 0.6 in.], containing both pads coated with $\mathrm{Ni} / \mathrm{Sn}$, was also mounted on the substrate using the film incorporating the solder powder.

\section{Reflow Process and Observation of the Self-assembly of the Solder}

The prepared specimens based on the glass chip and 3216 component were placed in a reflow chamber and heated in a nitrogen atmosphere using the heating program shown in Fig. 5. The test specimens were heated to $260^{\circ} \mathrm{C}$ at a rate of $4^{\circ} \mathrm{C} / \mathrm{s}$ (60 s from $20^{\circ} \mathrm{C}$ to $260^{\circ} \mathrm{C}$ ) that was maintained for $30 \mathrm{~s}$, and then cooled to $20^{\circ} \mathrm{C}$ at a rate of $\sim 4^{\circ} \mathrm{C} / \mathrm{s}$. Self-assembly of the solder based on the glass chip specimen was observed during the reflow process from the top view of the specimen using an optical microscope, operating at a long working distance (SMT Scope SK-5000, Sanyoseiko). The specimen based on the 3216 component was observed in a similar fashion, but from the side view of the specimen. 


\section{Differential Scanning Calorimetry (DSC) Measurements}

DSC measurements were performed on a Pyris differential scanning calorimeter (Perkin Elmer) to confirm the behaviors of the resin reaction and solder melting. The sample $(\sim 5 \mathrm{mg})$ was sealed in an aluminum pan and heated from $40^{\circ} \mathrm{C}$ to $280^{\circ} \mathrm{C}$ at a heating rate of $10^{\circ} \mathrm{C} / \mathrm{min}$ under a nitrogen atmosphere.

\section{X-ray Transmission Observation}

The self-assembly of the solder powder on the larger pads for the interconnection between the

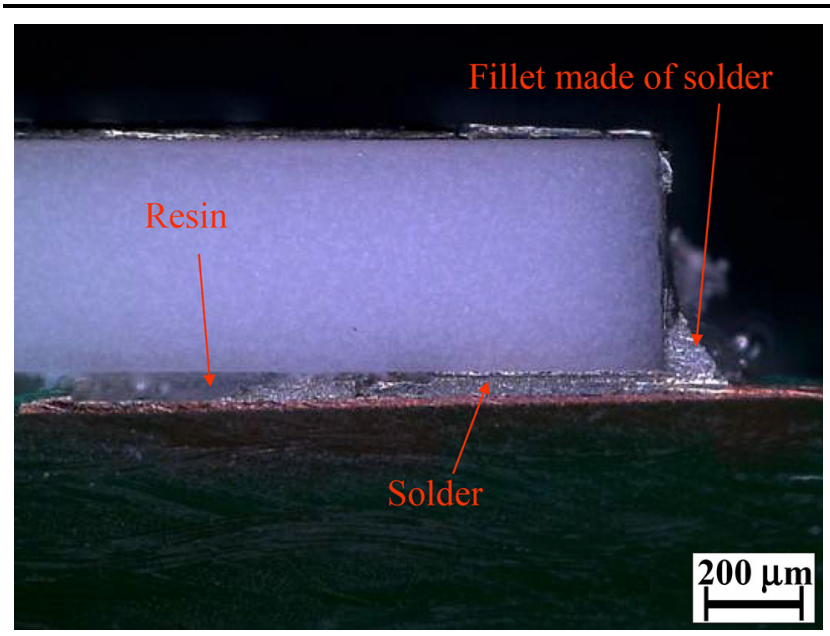

Fig. 11. Cross-sectional image of the interconnection between the 3216 component and substrate after the reflow process.
3216 component and substrate was observed with a micro-focus x-ray inspection system MF160C (Hitachi Kenki Finetech) after the reflow process.

\section{Mechanical Shear Test and Failure Observation}

The mechanical shear test was performed on a Dage Series 4000 (Inseto) as shown schematically in Fig. 6 to measure shear strength and observe failure mode. The test conditions were: shear speed $50 \mu \mathrm{m} / \mathrm{s}$; stand-off distance $200 \mu \mathrm{m}$; and temperature $\sim 15^{\circ} \mathrm{C}$. Each shear test specimen was prepared by soldering the 3216 component mounted on the ENIG surface of the FR-4 substrate using either reflowfilm or a solder paste (composed of Sn-3Ag$0.5 \mathrm{Cu}$ solder of $\sim 30 \mu \mathrm{m}$ diameter and rosin as fluxing agent) in the reflow process. A shear test using reflowfilm was also prepared by lamination at an appropriate pressure using tweezers on a hot plate at $180^{\circ} \mathrm{C}$ for $15 \mathrm{~s}$ (without reflow process). The shear strength measurements for each specimen were conducted in triplicate and an average value was calculated. Following the mechanical shear test, the failure surfaces were observed with a digital microscope (VHX-100 K; Keyence).

\section{Observation of the Soldering Interconnection Microstructure}

The microstructure of the soldering interconnection was analyzed on a scanning electron microscope (SEM; Royal Philips Electronics XL30 ESEM FEG) equipped with an energy-dispersive $\mathrm{x}$-ray
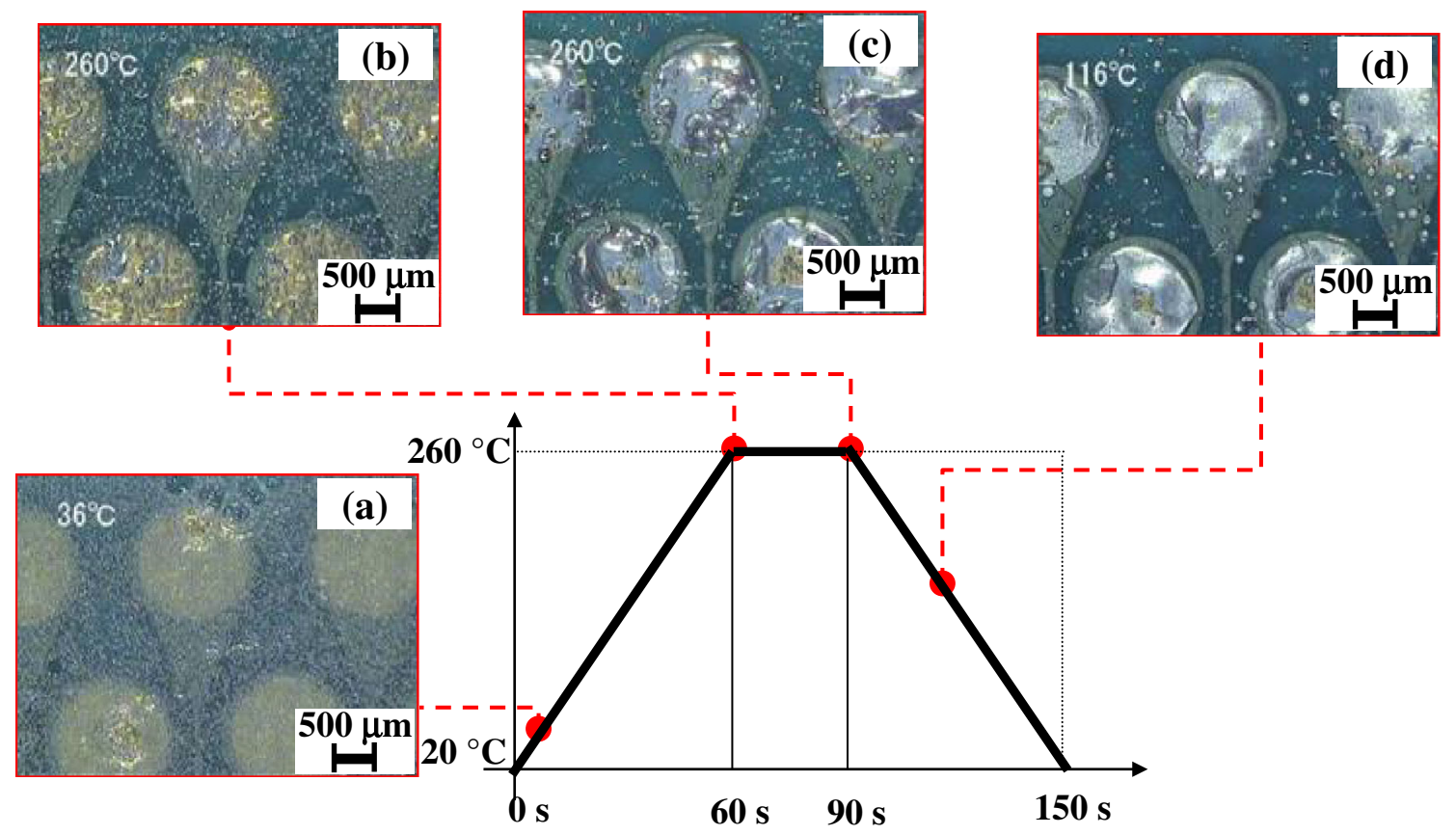

Fig. 12. Optical images of the glass chip specimen using the thermoplastic film incorporating Sn-3Ag-0.5Cu solder during the reflow process at (a) $36^{\circ} \mathrm{C}$ (during heating), (b) $260^{\circ} \mathrm{C}$ (following heating for $60 \mathrm{~s}$ ), (c) $260^{\circ} \mathrm{C}$ (following isothermal heating for $30 \mathrm{~s}$ ), and (d) $116^{\circ} \mathrm{C}$ (during cooling). 

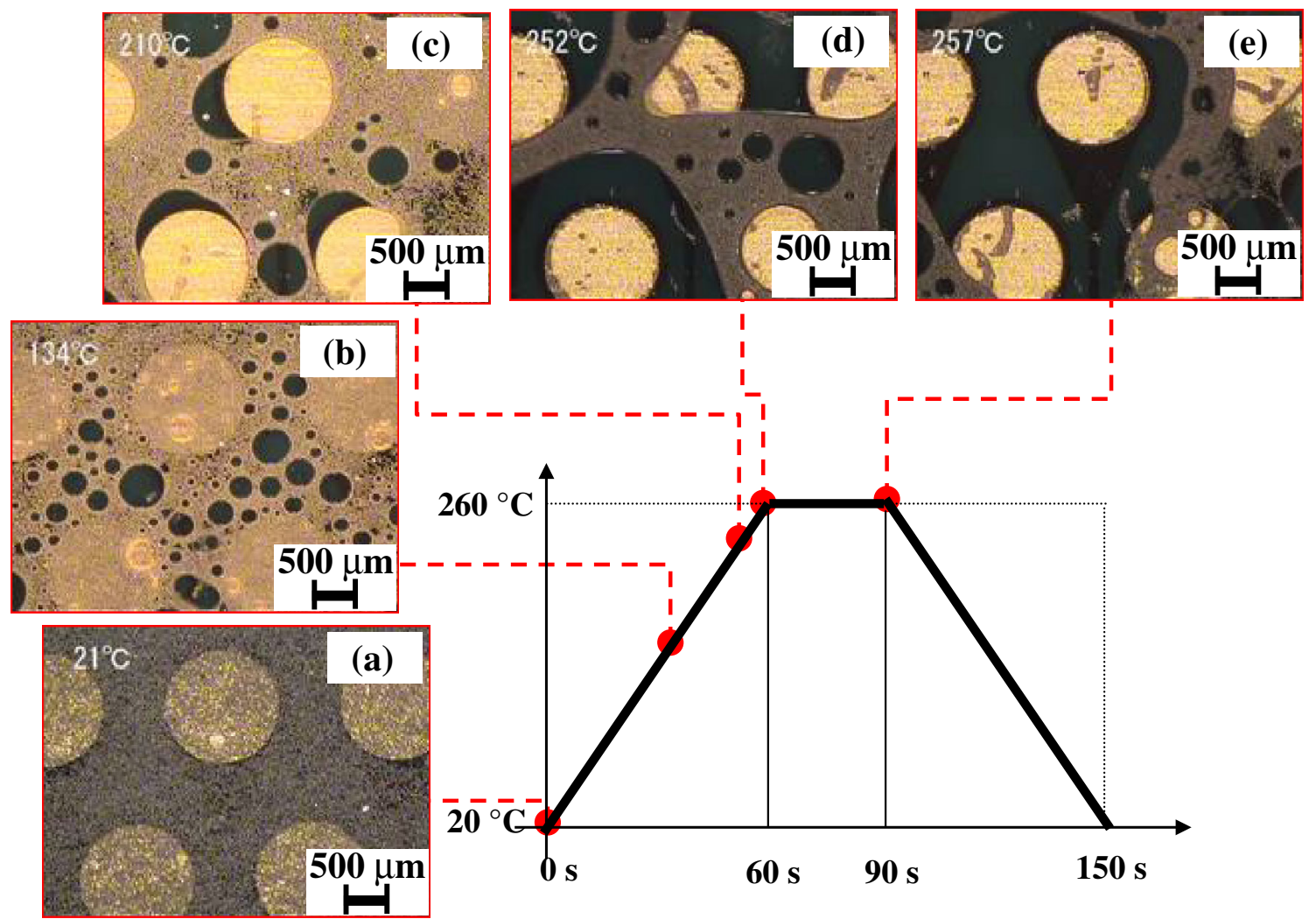

Fig. 13. Optical images of the glass chip specimen based on the epoxy paste incorporating Sn-3Ag-0.5Cu solder during the reflow process at (a) $21^{\circ} \mathrm{C}$ (before heating), (b) $134^{\circ} \mathrm{C}$ (during heating), (c) $210^{\circ} \mathrm{C}$ (during heating), (d) $\sim 260^{\circ} \mathrm{C}$ (during heating), and (e) $\sim 260^{\circ} \mathrm{C}$ (following isothermal heating for $30 \mathrm{~s}$ ).

spectroscope (EDX), operating at an accelerating voltage of $10 \mathrm{kV}$. Prior to SEM measurements, the specimen was prepared as follows. The specimen was impregnated with a liquid-type resin that was then cross-linked at room temperature. The specimen embedded within the cross-linked resin was polished on wet abrasive paper with varying grit numbers (JIS) from \#500 (average particle size: $30 \mu \mathrm{m}$ ) to \#2000 (average particle size: $10 \mu \mathrm{m}$ ) and finally with a $0.3-\mu \mathrm{m}$ alumina suspension. The polished specimen was etched by argon ion milling (IM400; Hitachi High-Technologies) to remove polish residue. Finally, platinum (Pt) was deposited on the exposed surface.

\section{RESULTS AND DISCUSSION}

Figure 7 shows a photographic image of the reflowfilm fabricated in this study that comprises a thermoplastic resin film containing the solder powder. The film as shown in Fig. 7 is one of the key features of reflowfilm that allows handling and easy repair when compared with the paste.

Figure 8 shows the DSC curves of the film and pastes containing the solder powder. All samples displayed a sharp endothermal peak at $218^{\circ} \mathrm{C}$ corresponding to the melting of $\mathrm{Sn}-3 \mathrm{Ag}-0.5 \mathrm{Cu}$ solder. The epoxy pastes displayed a broad exothermal peak, corresponding to the cross-linking reaction of epoxy, at a temperature lower than the melting point of solder. The onset temperatures of the exothermal peaks of the epoxy pastes in the presence and absence of flux agent were $40^{\circ} \mathrm{C}$ and $140^{\circ} \mathrm{C}$, respectively, suggesting that the flux agent accelerated the cross-linking reaction. Conversely, the thermoplastic film containing the solder powder showed no obvious exothermal peaks, suggesting that no cross-linking reaction had occurred.

Figure 9 shows the $\mathrm{x}$-ray transmission images of the interconnections between the 3216 component and substrate before and after the reflow process. The film containing the solder was used as soldering material. As shown in Fig. 9, the pads displayed nearly uniform contrast before reflow, indicating uniform distribution of the solder in the thermoplastic resin film. Conversely, the presence of the large dark domains observed in the post-reflow image as highlighted by the circle indicates the coalescence of the solder into large droplets owing to excellent wettability and Laplace pressure.

Figure 10 shows the reduction in the gap between the component and substrate, owing to the softening of the resin during the reflow process, thereby achieving excellent interconnection. Figure 11 shows the cross-sectional image of the 3216 component after the reflow process. As observed, a 


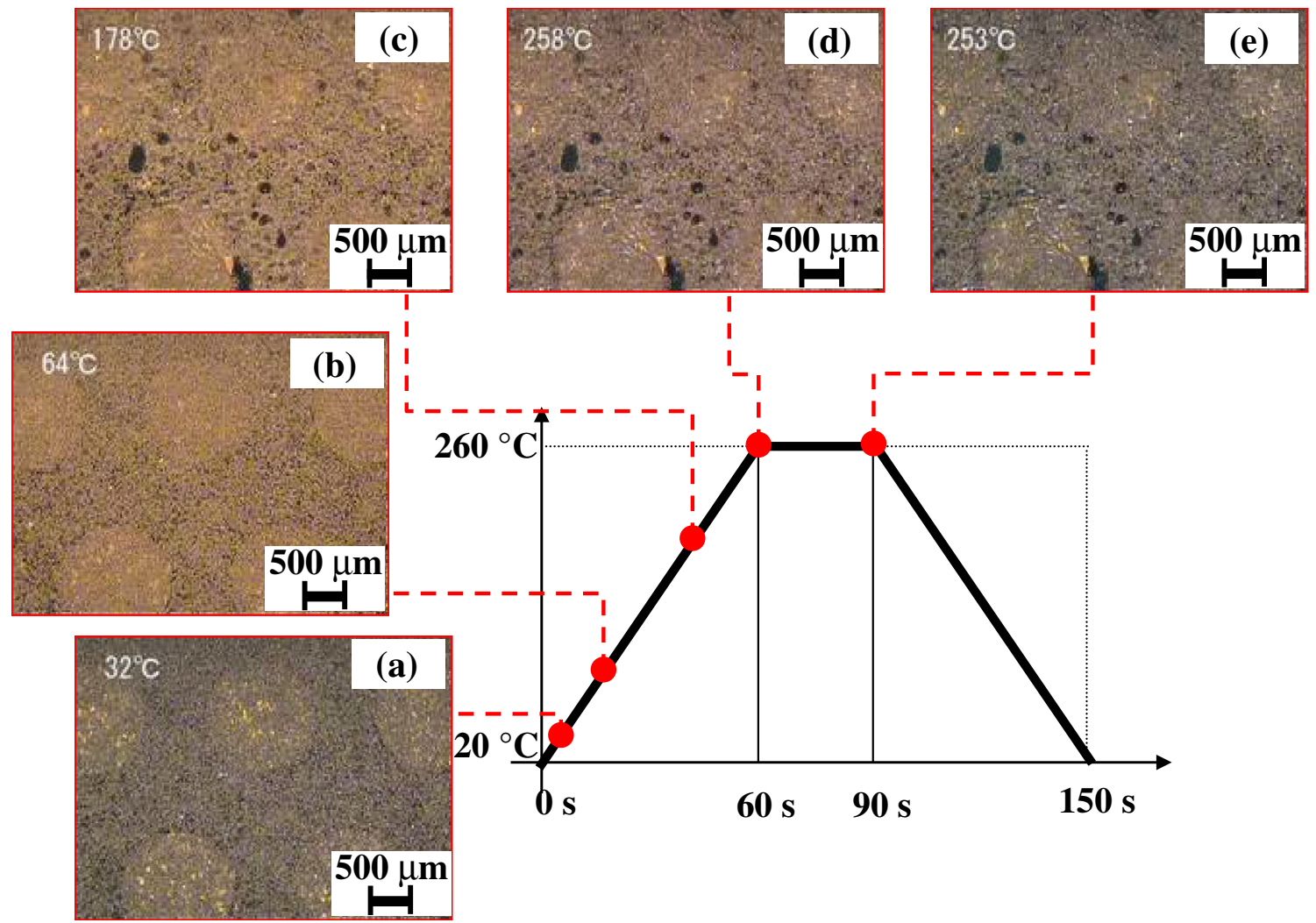

Fig. 14. Optical images of the glass chip specimen based on the epoxy paste incorporating Sn-3Ag-0.5Cu solder and fluxing agent during the reflow process at (a) $32^{\circ} \mathrm{C}$ (during heating), (b) $64^{\circ} \mathrm{C}$ (during heating), (c) $178^{\circ} \mathrm{C}$ (during heating), (d) $\sim 260^{\circ} \mathrm{C}$ (during heating), and $(\mathrm{e}) \sim 260^{\circ} \mathrm{C}$ (following isothermal heating for $30 \mathrm{~s}$ ).

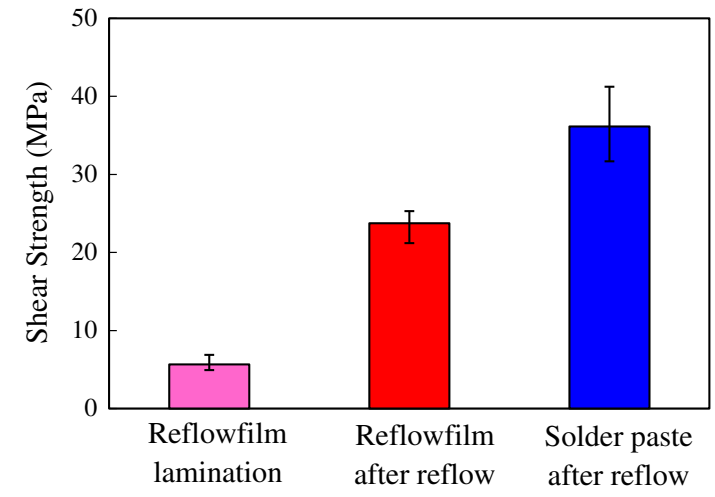

Fig. 15. Shear strength of the 3216 component mounted on the ENIG surface finish of the FR-4 substrate: (a) reflowfilm lamination, (b) reflowfilm after reflow, and (c) solder paste after reflow.

connecting path, as produced by soldering, and formation of the solder fillet were successful.

Figure 12 shows the optical images of the glass chip specimen using the film during the reflow process. As shown in Fig. 12, the solder on the pads was sufficiently wetted and assembled (coalesced into large droplets) after $30 \mathrm{~s}$ when maintained at $260^{\circ} \mathrm{C}$. A shiny surface was observed that confirmed the successful self-assembly of the solder using thermoplastic resin and without any fluxing agents. This indicates that the carboxyl group of the resin can effectively remove the oxidized solder on the surface.

Figure 13 shows optical images of the glass chip specimen during the reflow process. The soldering material used here was epoxy paste containing the solder and no fluxing additives. As clearly observed in Fig. 13, the voids generated at $134^{\circ} \mathrm{C}$ during the heating step coalesced into single larger voids with increasing temperatures. Moreover, coalesced solder droplets were not observed even at temperatures exceeding $218^{\circ} \mathrm{C}$ (corresponding to the melting point of solder), thereby suggesting the need for fluxing additives in the epoxy paste system.

Figure 14 shows optical images of the glass chip specimen during the reflow process. The soldering material used here was epoxy paste containing both the solder powder and fluxing agent. No noticeable migration of the solder powder was observed during the reflow process. This was consistent with our belief that the fluxing agent accelerated the crosslinking reaction of epoxy, as discussed in Fig. 8, and consequently inhibited self-assembly of the solder. 

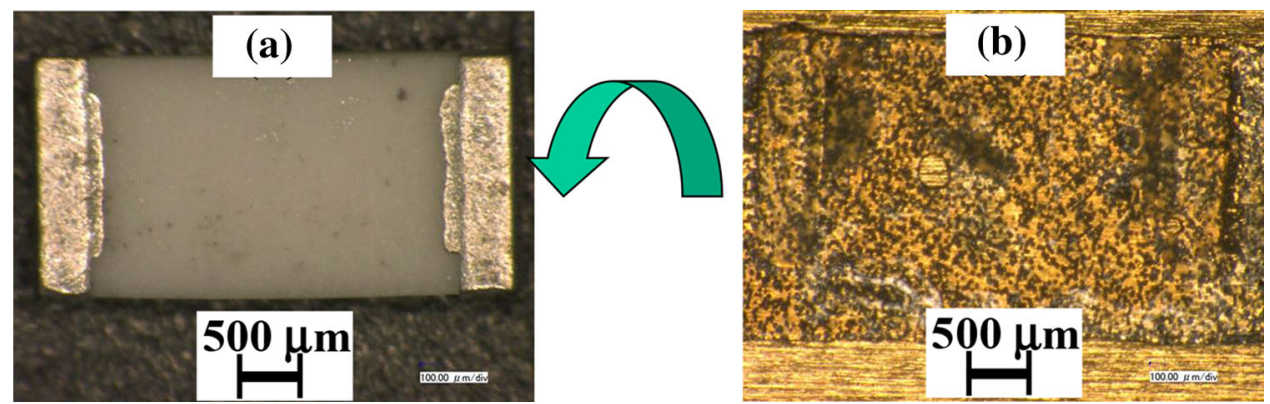

Fig. 16. Digital microscopy images of the failure surfaces of the (a) component and (b) substrate following mechanical shear test of the 3216 component mounted on the ENIG surface finish of the FR-4 substrate using reflowfilm on a hot plate at $180^{\circ} \mathrm{C}$ for $15 \mathrm{~s}$ at appropriate pressure.

Cohesive failure observed except in the encircled areas
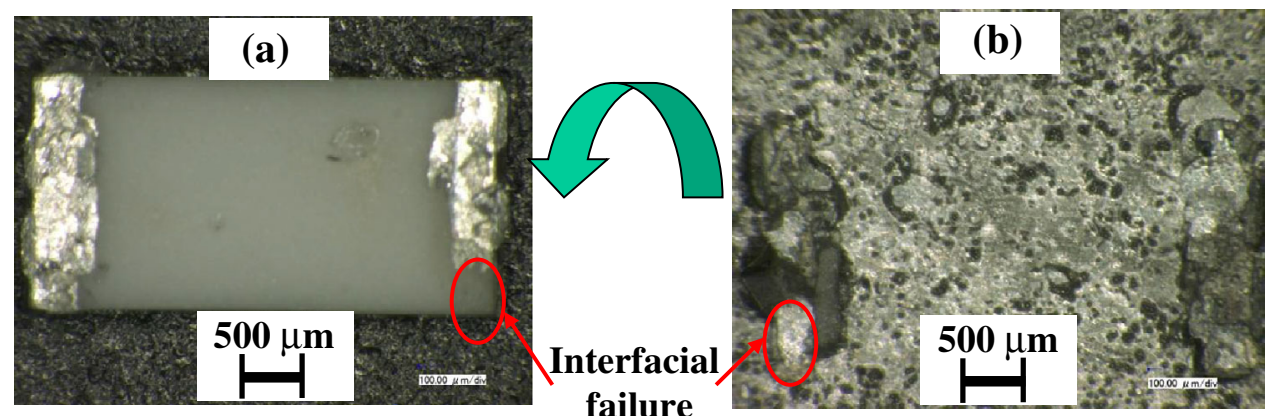

Fig. 17. Digital microscopy images of the failure surfaces of the (a) component and (b) substrate following mechanical shear test of the 3216 component mounted on the ENIG surface finish of the FR-4 substrate using reflowfilm under the reflow process.

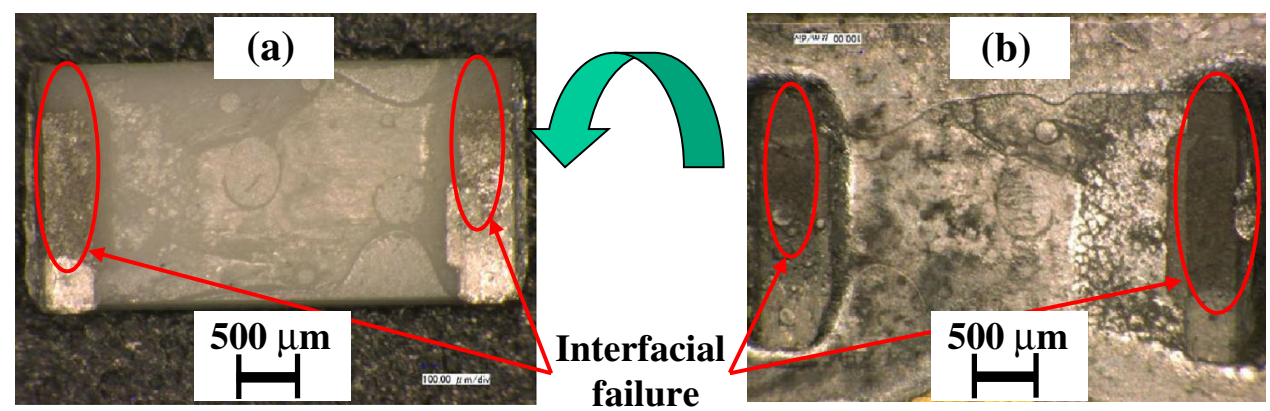

Fig. 18. Digital microscopy images of the failure surfaces of the (a) component and (b) substrate following mechanical shear test of the 3216 component mounted on the ENIG surface finish of the FR-4 substrate using solder paste under the reflow process.

Conversely, as shown in Fig. 12, self-assembly was successfully achieved when thermoplastic resin was used as the matrix. It is believed that the solder in the molten state migrates through the thermoplastic resin matrix to achieve self-assembly of the solder on the pads.

Figure 15 shows the shear strength of the 3216 component mounted on the ENIG surface finish of the FR-4 substrate. The data represent average values of the shear strength calculated from three measurements. The maximum and minimum deviations from the average values are represented by the corresponding error bars. The reflowfilm with lamination (without the reflow process) featured a shear strength of $5.7 \mathrm{MPa}$ and adequate adhesion property for handling. As observed from the failure surface in Fig. 16, delamination occurred at the interface between the 3216 component and the reflowfilm. Reflowfilm was only slightly damaged by delamination and could be repaired accordingly. The shear strength of the reflowfilm after the reflow process was $23.7 \mathrm{MPa}$ and significantly increased in comparison with that displayed by the reflowfilm with lamination. However, after the reflow process under a rapid cooling rate of $\sim 4^{\circ} \mathrm{C} / \mathrm{s}$, the shear strength of the reflowfilm (23.7 MPa) was lower 

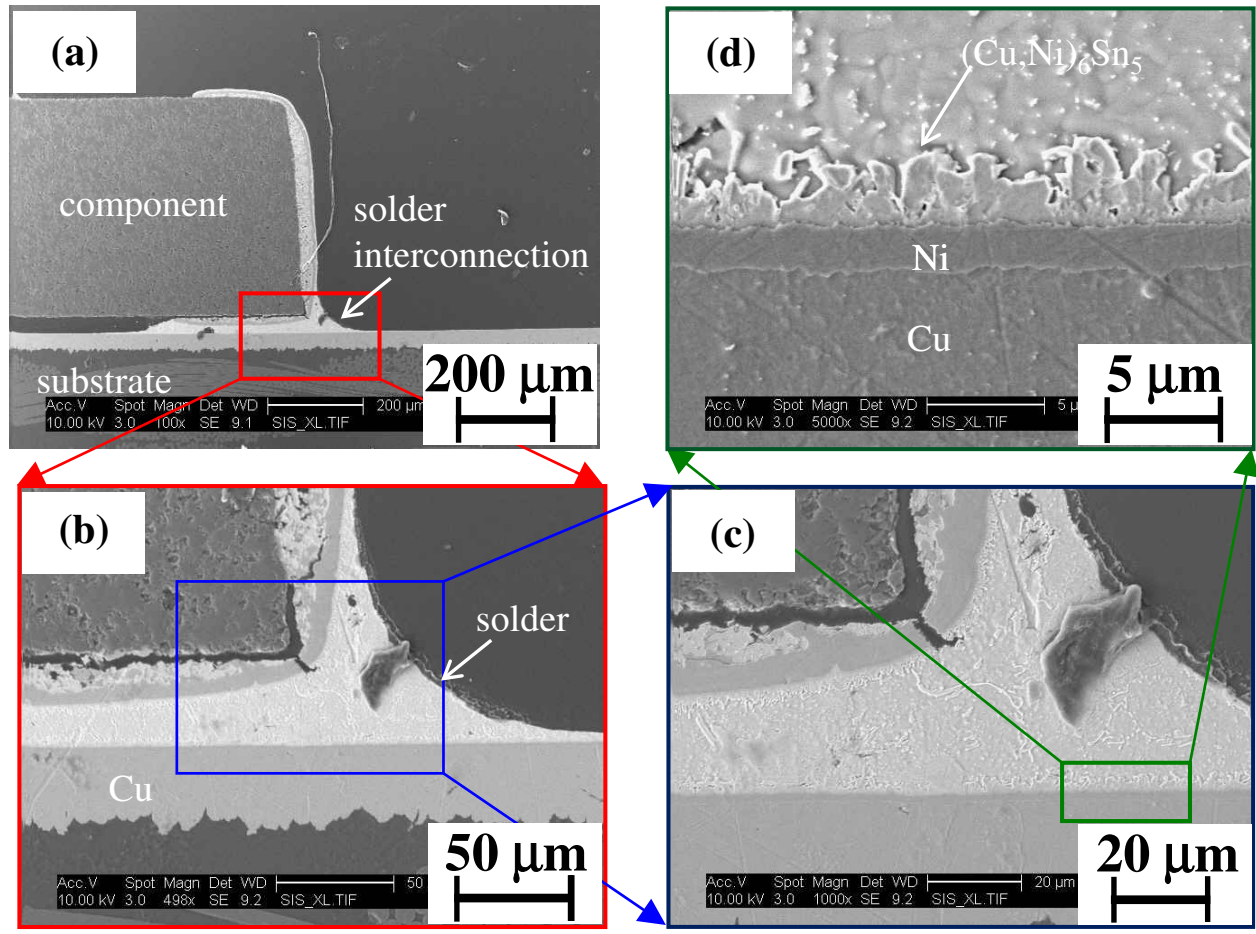

Fig. 19. Cross-sectional SEM images of the 3216 component mounted on the ENIG surface finish of the FR-4 substrate using solder paste under the reflow process under different magnifications showing (a) an overview image, (b) fillet from the enclosed section in (a), (c) solder interconnection from the enclosed section in (b), and (d) solder/substrate pad interface from the enclosed section in (c).
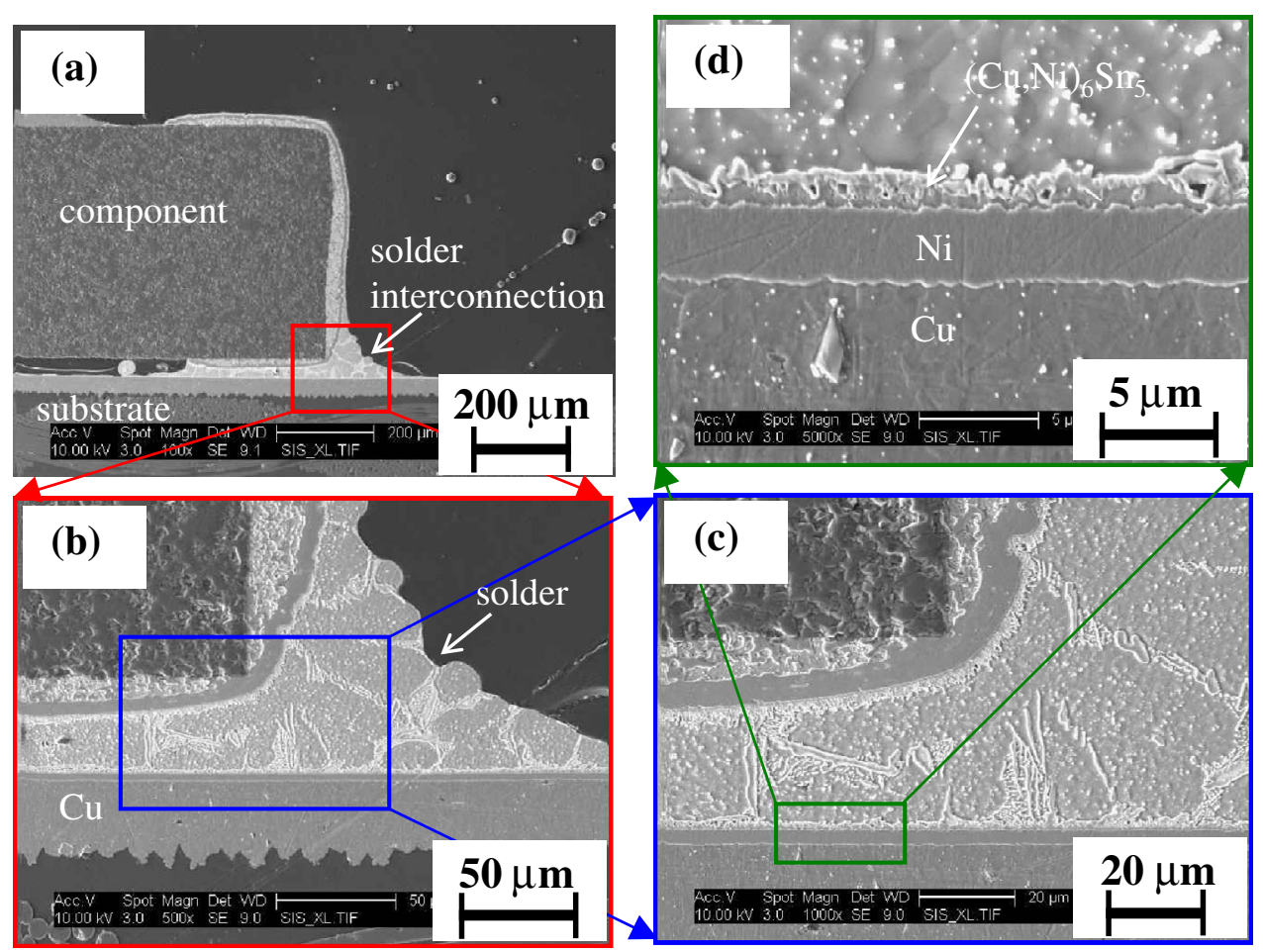

Fig. 20. Cross-sectional SEM images of the 3216 component mounted on the ENIG surface finish of the FR-4 substrate using reflowfilm under the reflow process under different magnifications showing (a) an overview image, (b) fillet from the enclosed section in (a), (c) solder interconnection from the enclosed section in (b), and (d) solder/substrate pad interface from the enclosed section in (c). 

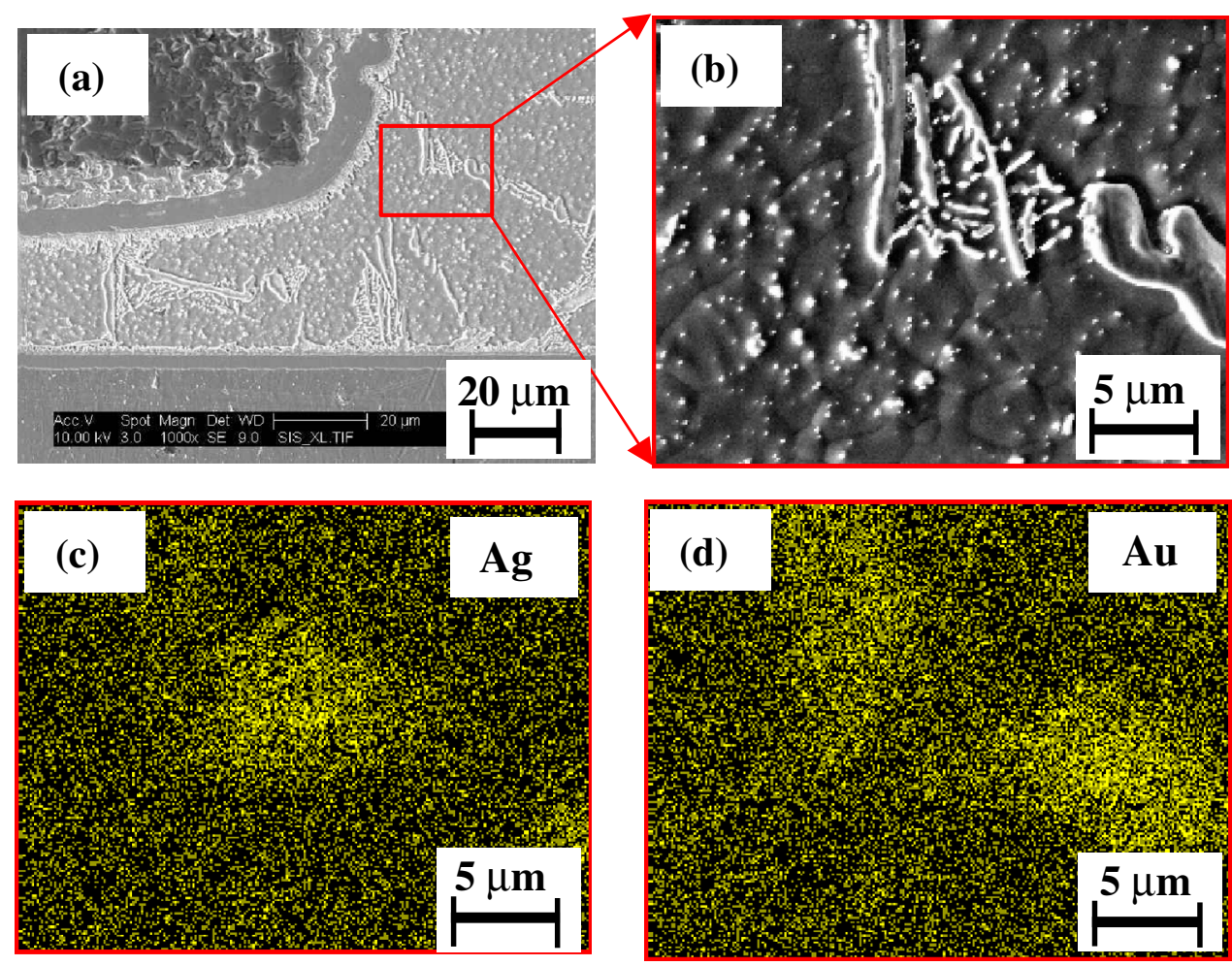

Fig. 21. Cross-sectional SEM images and corresponding EDX mapping images of the 3216 component mounted on the ENIG surface finish of the FR-4 substrate using reflowfilm under reflow process. SEM images showing (a) solder interconnection (also shown in Fig. 20c) and (b) IMC particles from the enclosed section in (a), and EDX mapping images showing the presence of (c) Ag in (b) and (d) Au in (b).

than that of conventional solder paste $(36.1 \mathrm{MPa})$. Figures 17 and 18 show digital microscopy images of the failure surfaces following a mechanical shear test using reflowfilm and solder paste, respectively, under the reflow process with rapid cooling. As shown in Fig. 17, for the reflowfilm system, interfacial failure between the 3216 component and the solder occurred in small areas, as enclosed in the circles. In the other areas that account for a large fraction of the failure, cohesive failure occurred because both the pads of the 3216 component and the ENIG surface finish of FR-4 substrate were covered with solder. However, as shown in Fig. 18, for the solder paste system, interfacial failure in the areas, as highlighted by the circle, accounted for the large fraction of failure observed.

Figures 19 and 20 show the cross-sectional SEM images for the solder paste and reflowfilm systems after the reflow process with rapid cooling. It is well known that the thin Au coating of ENIG rapidly dissolves in bulk solder, and that an IMC layer of $(\mathrm{Cu}, \mathrm{Ni})_{6} \mathrm{Sn}_{5}$ is formed on the $\mathrm{Ni}$ surface during the reflow process. ${ }^{32}$ As shown in Fig. 19, using solder paste, a $(\mathrm{Cu}, \mathrm{Ni})_{6} \mathrm{Sn}_{5}$ layer was observed on the $\mathrm{Ni}$ surfaces of the 3216 component and the substrate. The occurrence of interfacial failure (macroscopic crack propagation at the interface between $\mathrm{Ni}$ and solder) upon shear test of the reflowed specimen using solder paste is possibly because of the brittle property of the $(\mathrm{Cu}, \mathrm{Ni})_{6} \mathrm{Sn}_{5}$ layer. Similarly, as shown in Fig. 20, the reflowed specimen using reflowfilm also featured a $(\mathrm{Cu}, \mathrm{Ni})_{6} \mathrm{Sn}_{5}$ layer on the $\mathrm{Ni}$ surfaces. Moreover, an IMC network throughout the bulk was observed in the solder interconnection. The network was composed of large needle- and plate-like IMC particles. Based on the EDX analysis shown in Fig. 21, the large needle-shaped IMC particles may correspond to $\mathrm{Ag}_{3} \mathrm{Sn}$ because analysis revealed the presence of $\mathrm{Ag}$, whereas the large plate-shaped IMC particles may correspond to $\mathrm{Au}_{4} \mathrm{Sn}$ because analysis revealed the presence of $\mathrm{Au}$. It is well known that needle-shaped $\mathrm{Ag}_{3} \mathrm{Sn}$ and plate-shaped $\mathrm{Au}_{4} \mathrm{Sn}$ are formed in solder bulk during $\mathrm{Sn}-\mathrm{Ag}-\mathrm{Cu}$ soldering on ENIG surface finish (reflow), isothermal aging, and thermo-mechanical cycling (TMT). 1,28,33-37 Large IMC particles, exhibiting brittle properties, greatly affect plastic deformation of solder. ${ }^{33,38}$ As a result, the straindelocalized boundary between large IMC particles and $\mathrm{Sn}$ (solder matrix) can trigger crack propagation. ${ }^{33,39}$ Crack propagation through solder bulk (macroscopic cohesive failure) upon shear test of the reflowed specimen using reflowfilm may occur near the boundary between IMCs and Sn (solder matrix) owing to strain localization (microscopic interfacial failure). The onset of macroscopic cohesive failure is mainly because of the less robust network interface between IMCs $\left(\mathrm{Ag}_{3} \mathrm{Sn}, \mathrm{Au}_{4} \mathrm{Sn}\right)$ and $\mathrm{Sn}$ (solder matrix) when compared with that of the layer interfaces $\mathrm{Ni} /(\mathrm{Cu}, \mathrm{Ni})_{6} \mathrm{Sn}_{5}$ and $(\mathrm{Cu}, \mathrm{Ni})_{6} \mathrm{Sn}_{5} /$ solder. 
However, a distinct network structure composed of IMCs for the reflowed specimen using solder paste was not observed in the solder bulk. This indicated that macroscopic interfacial failure had mainly occurred.

The reflowed specimen of reflowfilm showed lower shear strength when compared with that of solder paste possibly because of the IMCs network of solder bulk. However, the $(\mathrm{Cu}, \mathrm{Ni})_{6} \mathrm{Sn}_{5}$ layer thickness, which is responsible for poor reliability, was $\sim 1.7 \mu \mathrm{m}$ for the reflowed specimen of reflowfilm (Fig. 20d) and $\sim 2.1 \mu \mathrm{m}$ for that of solder paste (Fig. 19d). It should be pointed out that the thickness of the Ni layer decreased during the reflow process according to the extent of $\mathrm{Ni}$ mass transfer to IMC. Before reflow, both the reflowfilm and solder paste systems displayed the same $\mathrm{Ni}$ layer thickness. Thus, considering the above points, reflowfilm is more advantageous. Therefore, suppression of the IMC network formation is required for its reliability. It is well known that cooling rate has a great effect on IMC formation as observed for $\mathrm{Ag}_{3} \mathrm{Sn}$ in solder bulk. ${ }^{38}$ Further study is required to evaluate the size and distribution of IMC, and their shear strength under a standard reflow process with a slower cooling rate.

\section{CONCLUSIONS}

The self-assembly of Sn-3Ag-0.5Cu solder on pads in polymeric materials was investigated using DSC, optical microscopy, and x-ray transmission analyses. The shear strength of the interconnection using reflowfilm with lamination and after reflow with rapid cooling was measured. Microstructure analysis was conducted using SEM. The conclusions are as follows:

(1) Thermoplastic resin film containing Sn-3Ag$0.5 \mathrm{Cu}$ solder powder that facilitates handling and repair was successfully fabricated. The film was named reflowfilm.

(2) No distinct exothermal peaks corresponding to a cross-linking reaction were detected by DSC for the film. Self-assembly of the solder and formation of the connective path of the solder between the component and substrate were successfully achieved using the film.

(3) The film (reflowfilm) contains carboxyl groups in the thermoplastic resin and no fluxing additives were required to achieve excellent solder wettability.

(4) The epoxy paste lacked sufficient flux activity. The epoxy paste containing fluxing agent prevented migration of the solder powder, probably because of the accelerated cross-linking reaction caused by the fluxing agent.

(5) The shear strength of the reflowfilm with lamination was sufficient and significantly increased during reflow process. Delamination damage of the reflowfilm was sufficiently low for repair. However, the shear strength of the interconnection using reflowfilm, showing cohesive failure, possibly because of the brittle IMC $\left(\mathrm{Ag}_{3} \mathrm{Sn}, \mathrm{Au}_{4} \mathrm{Sn}\right)$ network in bulk, was lower than that of conventional solder paste that showed interfacial failure.

\section{ACKNOWLEDGEMENTS}

The authors thank N. Furukawa, K. Urashima and M. Kobune from Hitachi Chemical Co. Ltd. for support with the experiments.

\section{REFERENCES}

1. M. Lee, M. Yoo, J. Cho, S. Lee, J. Kim, C. Lee, D. Kang, C. Zwenger, and R. Lanzone, Proceedings of the 59th Electronic Components and Technology Conference (San Diego, CA: IEEE, 2009), pp. 720-723.

2. K. Lee, I.J. Saarinen, L. Pykari, and K.W. Paik, IEEE Trans. Compon. Packag. Manuf. Technol. 1, 1901 (2011)

3. Y.-S. Eom, K.-S. Jang, J.-T. Moon, and J.-D. Nam, ETRI J. 32,414 (2010)

4. R.R. Tummala, V. Sundaram, P.M. Raj, R. Pucha, T. Bandyopadhyay, N. Kumbhat, V. Sridharan, T. WakdenMonroe, and D. Suttrer, Chip Scale Rev. 14, 14 (2010).

5. J.H. Lau, ed., Flip Chip Technologies (New York: McGrawHill, 1995), pp. 155-179.

6. K. Yasuda, J.-M. Kim, M. Yasuda, and K. Fujimoto, Mater. Trans. 45, 799 (2004).

7. K. Yasuda, J.-M. Kim, and K. Fujimoto, J. Electron. Packag. 127, $12(2005)$

8. J.-M. Kim, K. Yasuda, and K. Fujimoto, J. Electron. Mater. 34,600 (2005).

9. K. Yasuda, J.-M. Kim, M. Yasuda, and K. Fujimoto, Jpn. J. Appl. Phys. 43, 2277 (2004)

10. J.-M. Kim, K. Yasuda, and K. Fujimoto, J. Electron. Mater. 33, 1331 (2004).

11. J.-M. Kim, K. Yasuda, M. Rito, and K. Fujimoto, Mater. Trans. 45, 157 (2004).

12. D.H. Gracias, J. Tien, T.L. Breen, C. Hsu, and G.M. Whitesides, Science 289, 1170 (2000).

13. G.M. Whitesides and B. Grzybowski, Science 295, 2418 (2002).

14. W. Zheng, P. Buhlmann, and H.O. Jacobs, Proc. Natl. Acad. Sci. USA 101, 12814 (2004).

15. Y.-S. Eom, J.-W. Beak, J.-T. Moon, J.-D. Nam, and J.-M. Kim, Microelectron. Eng. 85, 327 (2008).

16. Y.-S. Eom, K. Jang, J.-T. Moon, J.-D. Nam, and J.-M. Kim, Microelectron. Eng. 85, 2202 (2008).

17. S. Karashima, T. Kitae, S. Sawada, S. Nakatani, T. Ogawa, M. Koyama, S. Matsuoka, Y. Taniguchi, N. Tsukahara, K. Hotehama, and Y. Kitade, Proceedings of International Conference on Electronics Packaging 2010 (Sapporo, Japan, 2010), pp. 190-193.

18. K. Yasuda, IEEE Trans. Compon. Packag. Manuf. Technol. 1,1895 (2011).

19. K. Ohta, K. Yasuda, M. Matsushima, and K. Fujimoto, J. Phys.: Conf. Ser. 165, 012047 (2009).

20. K. Yasuda, J. Solid Mech. Mater. Eng. 3, 1356 (2009).

21. Q.K. Zhang, Q.S. Zhu, H.F. Zou, and Z.F. Zhang, Mater. Sci. Eng. A 527, 1367 (2010).

22. P.L. Liu and J.K. Shang, J. Mater. Res. 16, 1651 (2001).

23. A.Y. Lozovoi, A.T. Paxton, and M.W. Finnis, Phys. Rev. B 74, 155416 (2006).

24. V.J. Keast, J. Bruley, P. Rez, J.M. Maclaren, and D.B. Williams, Acta Mater. 46, 481 (1998).

25. P.L. Liu and J.K. Shang, Scr. Mater. 44, 1019 (2001).

26. H.F. Zou, Q.K. Zhang, and Z.-F. Zhang, J. Mater. Res. 26, 449 (2010).

27. P.L. Liu and J.K. Shang, J. Mater. Res. 20, 818 (2005).

28. K.S. Kim, S.H. Huh, and K. Suganuma, J. Alloys Compd. 352,226 (2003).

29. Japan Electronics and Information Technology Industries Association (JEITA), Lead-free roadmap 2002, ver. 2.1. 
30. K. Suganuma, ESPEC Technol. Rep. 13, 1 (2002).

31. C.E. Ho, S.C. Yang, and C.R. Kao, J. Mater. Sci.: Mater. Electron. 18, 155 (2007).

32. T.T. Mattila and J.K. Kivilahti, J. Electron. Mater. 34, 969 (2005).

33. S.K. Kang, W.K. Choi, D.-Y. Shih, D.W. Henderson, T. Gosselin, A. Sarkhel, C. Goldsmith, and K.J. Puttlitz, JOM 55, 61 (2003)

34. S. Terashima, Y. Kariya, T. Hosoi, and M. Tanaka, J. Electron. Mater. 32, 1527 (2003).
35. J.-Y. Park, C.-U. Kim, T. Carper, and V. Puligandla, J. Electron. Mater. 32, 1297 (2003).

36. K.S. Lin, H.Y. Huang, and C.P. Chou, J. Mater. Eng. Perfom. 18, 182 (2009).

37. J. Pan, J. Silk, M. Powers, and P. Hyland, IEEE Trans. Compon. Packag. Manuf. Technol. 1, 1662 (2011).

38. K.S. Kim, S.H. Huh, and K. Suganuma, Mater. Sci. Eng. A 333, 106 (2002).

39. D.R. Frear, J.W. Jang, J.K. Lin, and C. Zhang, JOM 53, 28 (2001). 